\title{
PRELIMINARY DEVELOPMENT OF LOCOMOTIVE CRASHWORTHY COMPONENTS
}

\author{
Patricia Llana \\ Volpe National Transportation Systems Center \\ US Department of Transportation \\ Cambridge, MA 02142 USA \\ Richard Stringfellow \\ TIAX, LLC \\ Lexington, MA 02421 USA
}

\begin{abstract}
The Federal Railroad Administration (FRA) and the Volpe Center are continuing to evaluate new technologies for increasing the safety of passengers and operators in rail equipment. In recognition of the importance of override prevention in train-to-train collisions in which one of the vehicles is a locomotive, and in light of the success of crash energy management technologies in cab car-led passenger trains, the Volpe Center seeks to evaluate the effectiveness of components that could be integrated into the end structure of a locomotive that are specifically designed to mitigate the effects of a collision and, in particular, to prevent override of one of the lead vehicles onto the other. This paper provides preliminary results of a research program that aims to develop, fabricate and test two crashworthy components for the forward end of a locomotive: (1) a deformable anti-climber, and (2) a push-back coupler.
\end{abstract}

\section{INTRODUCTION}

In the event of a collision between two trains, a considerable amount of energy must be dissipated. One of the potential consequences of such a collision is override of one of the vehicles onto the other. Locomotives, because of their great longitudinal strength and stiffness, are particularly susceptible to override when they collide with another vehicle, and the consequences can be catastrophic. Research has shown that conventional anti-climbing structures can deform on impact and form a ramp, increasing the likelihood of override [1]. As they crush longitudinally, conventional anti-climbers lose their vertical load carrying capacity due to the substantial fracture that occurs as the anti-climber crushes. The longitudinal crush of the anti-climber causes fracture in the webs behind the face of the anti-climber. These fractured webs can still resist a longitudinal compression load, but can no longer transmit a vertical shear load. This loss of vertical load-carrying capacity in conventional anti-climbers often leads to ramp formation, which promotes override. Such behavior was exhibited in a head-on collision that occurred in West Eola, Illinois on January 20, 1993. As seen in Figure 1, the accident resulted in one locomotive (right side of photo) overriding the other locomotive, crushing the operator's cab. The photograph shows the overriding locomotive lifted off of its lead truck. In order to be effective, an anti-climber must engage the end structures of opposing equipment and provide sufficient vertical load capacity.

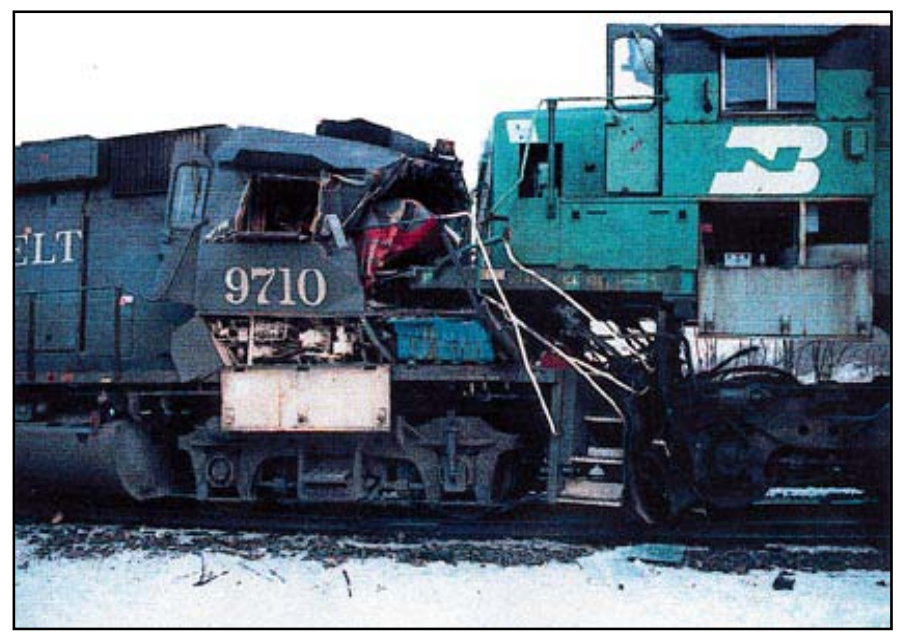

Figure 1. West Eola, Illinois Head-On Collision, January 20, 1993 [1]. 
Research has shown that the addition of a few structural features to the forward end of a locomotive can greatly reduce the propensity for override [2]. Such features include the following:

1. Push-back couplers, and

2. Deformable anti-climbers.

Push-back couplers allow the ends of the vehicles to engage prior to the build-up of large forces and moments that might lead to lateral buckling of the vehicles with respect to one another. Deformable anti-climbers provide sufficient vertical load carrying capacity as they deform gracefully and predictably to prevent the formation of a ramp. Crushable zones within deformable anti-climbers absorb collision energy so as to prevent uncontrolled deformation of interlocking features that might cause formation of a ramp.

The Volpe Center is supporting the FRA in the development of a crash energy management (CEM) system for locomotives. In a previous research program, the Volpe Center developed several concepts for a more crashworthy locomotive [2]. The study addressed the feasibility of incorporating pushback couplers and deformable anti-climbers into locomotives. Conceptual design goals included the preservation of occupant volume and the maintenance of vehicle-rail contact, i.e., the prevention of override, while ensuring that the equipment was compatible with existing operating requirements. Building on this previous work, the objectives of the current research program are to develop detailed designs for a push-back coupler and a deformable anti-climber, develop test article designs for the components, construct the test articles, conduct the component tests, and refine the designs based on the results of the tests.

\section{DESIGN REQUIREMENTS}

The first phase of the research program was aimed at defining design requirements for a platform-style locomotive with increased crashworthiness due to the incorporation of a pushback coupler and deformable anti-climber. These requirements govern the development of designs for push-back coupler and deformable anti-climber components, and include collision scenarios for evaluating their behavior in a collision with another vehicle. The design requirements are comprised of performance requirements, geometric requirements, operational requirements, and fabrication requirements. The energy absorption requirements and many of the other crashworthiness specifications are derived from experience gained in other crashworthiness programs. Most of the strength requirements and some of the crashworthiness specifications are derived from the APTA [3] and AAR [4] standards. All of the requirements are consistent with CFR 49, Part 229 [5], APTA SS-C\&S-034-99, Rev 2 [3], and APTA RP-C\&S-XXX [6].

\section{Performance Requirements Push-back Coupler}

- Trigger mechanism: shear bolt or deformation tube arrangement

- Trigger load: minimum 600,000 lbf/maximum 800,000 lbf
- Push-back requires end frames of colliding equipment to engage

- Stroke: The push-back coupler must be capable of pushing back with enough stroke to accommodate and capture conventional locomotive, cab car and freight car couplers. The minimum will be based on interaction with cab and freight cars, and the maximum based on open space behind draft pocket.

- Energy absorption: must absorb energy in a controlled manner while pushing back; minimum 600,000 ft-lbf (based on stroke and load characteristics)

- Support structure: no permanent deformation prior to exhaustion of push-back coupler stroke; crippling load of support structure must not be exceeded in a $12 \mathrm{mph}$ impact into another consist

- Torsional resistance: minimum 150,000 ft-lbf prior to pushback and after exhaustion of push-back function

- Retention device: must be strong enough to support 150,000 lbf tension load at any time during push-back and after exhaustion of push-back function

- No material failure

Deformable Anti-climber

- Trigger mechanism: plastic deformation/progressive buckling of energy absorbers

- Trigger load: minimum 800,000 lbf/maximum 1,200,000 lbf

- Stroke: minimum 10 inches (based on operational requirements, geometric requirements, and interaction with cab and freight cars)

- Energy absorption: minimum 700,000 ft-lbf (based on stroke and load characteristics)

- Vertical strength: 100,000 lbf in both un-deformed and fully-deformed configurations

- Support structure: strong enough to support crush load without failing or undergoing large plastic deformation; crippling load of support structure must not be exceeded in a 12 mph impact into another consist

- No material failure

\section{Collision Scenarios}

A locomotive design featuring the two crashworthy components developed in this program would necessarily be placed in service along with conventional equipment. For this reason, the consequences of three different collision scenarios must be evaluated:

1. Modified locomotive to conventional locomotive

2. Modified locomotive to cab car

3. Modified locomotive to freight car

The collision speed for each scenario will be defined so as to exhaust the stroke of both the deformable and push-back coupler energy absorption systems and initiate loading of the locomotive underframe. Each scenario will be evaluated for three conditions:

1. Vehicles perfectly aligned

2. Modified locomotive offset upward by 6.0 inches

3. Modified locomotive offset downward by 6.0 inches 
Performance in each scenario will be evaluated through largedeformation dynamic finite element analysis (FEA).

The following criteria shall be used to evaluate satisfaction of the requirements relative to the collision scenarios:

- No override of one vehicle onto another

- No formation of a ramp that might eventually lead to override

- No uncontrolled deformation in modified locomotive

- No uncontrolled deformation in conventional vehicles

- A best-fit straight line approximation of the force/crush data shall exhibit a positive slope until the crush for the crashworthy components is exhausted and the underframe begins to crush.

- The strength of the underframe shall be at least 50\% higher than the crush strength of the combined deformable anticlimber/push-back coupler system.

- The underframe must be strong enough to support the loads on the deformable anti-climber and push-back coupler without undergoing large deformation.

\section{Geometric Requirements \\ Push-back Coupler}

- Designed to fit into a standard locomotive draft gear compartment

- Cannot interfere with existing locomotive structures during and following push-back to its complete stroke

\section{Deformable Anti-climber}

- Width: must extend laterally, at a minimum, to the approximate $1 / 3$ points across the width of the end of the locomotive; must also extend laterally to the main longitudinal beams of the locomotive

- Depth: center must extend to within 4 inches of the pulling face of the coupler with the draft gear fully compressed and must extend no less than 10" from the locomotive front plate for its required width

- Cannot interfere with other equipment, unless it is agreed that such equipment can be easily re-routed

\section{Operational Requirements}

- Low-speed coupling: The push-back coupler system must be able to withstand a hard couple between two locomotives at a speed of $5 \mathrm{mph}$ without triggering the push-back system.

- Curving: The components of the locomotive shall not interfere for operation with nominally identical vehicles operating on curves up to 23 degrees.

\section{Fabrication Requirements General}

- The design should utilize materials and fabrication methods that a normal metal fabrication company could use.

\section{Materials}

- The materials of construction for the primary structure and the energy absorbing elements shall be either high strength low alloy (also known as low-alloy, high tensile) or austenitic stainless steels commonly used in the fabrication of modern railway vehicles for operation in North America. Aluminum honeycomb may be used for energy absorbers.

\section{Construction Methods}

- All primary structural members shall be welded in accordance with AWS D1.1. Bolting may be used for the push-back coupler trigger mechanism.

\section{Overall Vehicle Integration}

- The push-back coupler and deformable anti-climber components shall be designed so that they can be integrated onto an existing passenger locomotive.

\section{PRELIMINARY DESIGNS \\ Deformable Anti-climber}

The specific locomotive platform chosen for development was a MotivePower MPXpress MP40. The preliminary design for the deformable anti-climber employs four progressive buckling tubes: two located at the base of the short hood, and two located beneath them. Figure 2 shows a view of the deformable anticlimber from above, and Figure 3 from below. The upper progressive buckling tubes are connected laterally by a ribbed plate. All progressive buckling tubes are welded onto the front plate of the locomotive, as shown in Figure 4. Support structures have been added between the two main longitudinal beams of the underframe for the purpose of transferring impact loads into the underframe. A side view of the front end of the vehicle showing the progressive buckling tubes as well as the support structure can be seen in Figure 5. The locations of the progressive buckling tubes are chosen for optimum engagement with the ends of the conventional locomotive, the cab car, and the freight car.

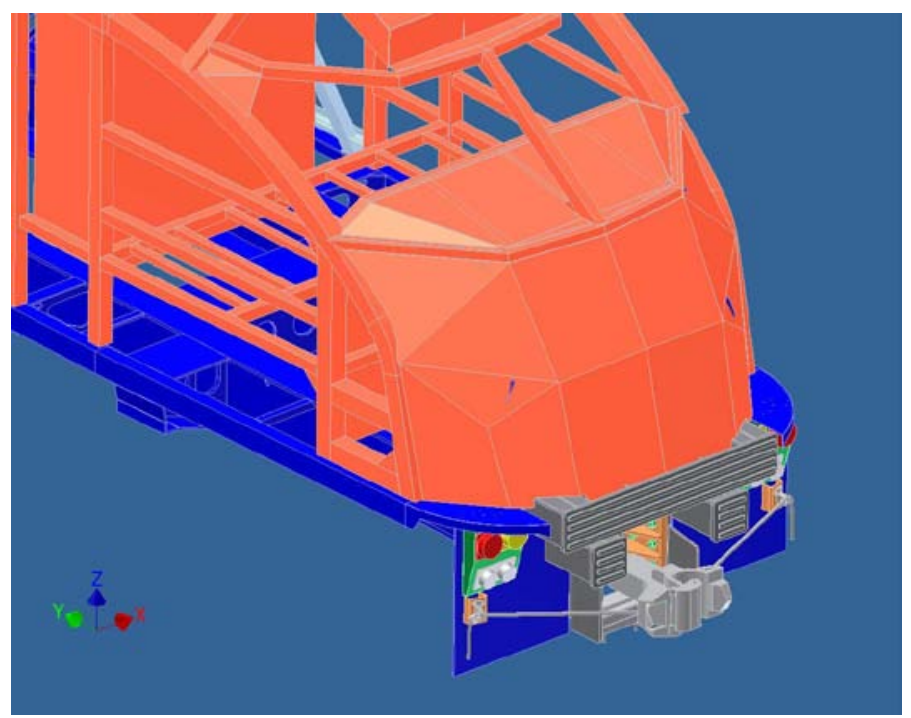

Figure 2. Top view of the deformable anti-climber/pushback coupler system retrofitted onto a MotivePower MP40. 


\section{Push-back Coupler}

The preliminary design for the push-back coupler employs an H-type coupler attached to a push-back yoke and deformation tube. Figure 6 shows a bottom view of the push-back coupler inside the draft gear pocket of the locomotive. The draft gear pocket has been redesigned to provide more than 10 inches of additional stroke. The push-back coupler is attached to the draft gear pocket by the coupler support assembly (shown in yellow) with 12 shear bolts, six on each side. The six shear bolts on the right side are shown in Figure 7 in green. These bolts are designed to fail once the energy-absorbing stroke of the pushback coupler has been exhausted, thereby shifting the load path from the push-back coupler to the deformable anti-climber.

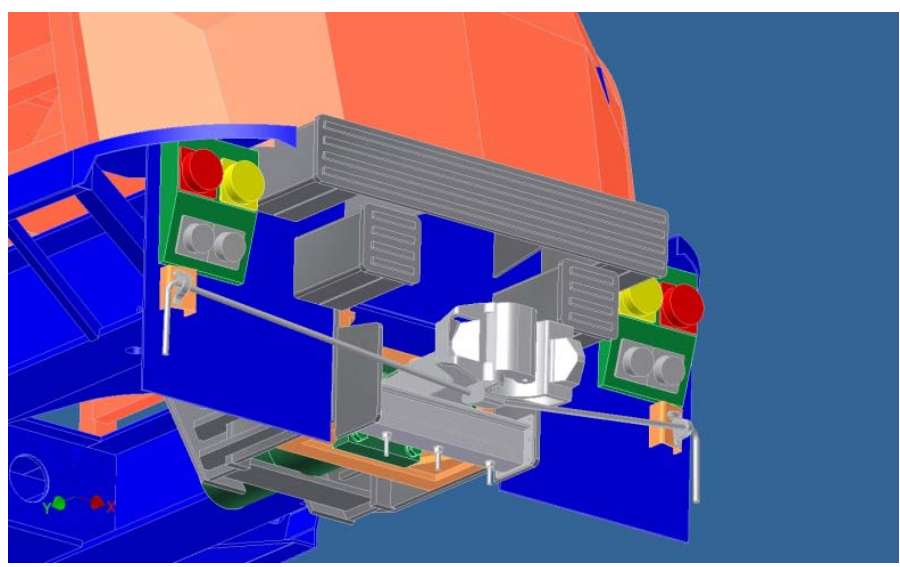

Figure 3. Bottom view of the deformable anti-climber/pushback coupler system retrofitted onto a MotivePower MP40.

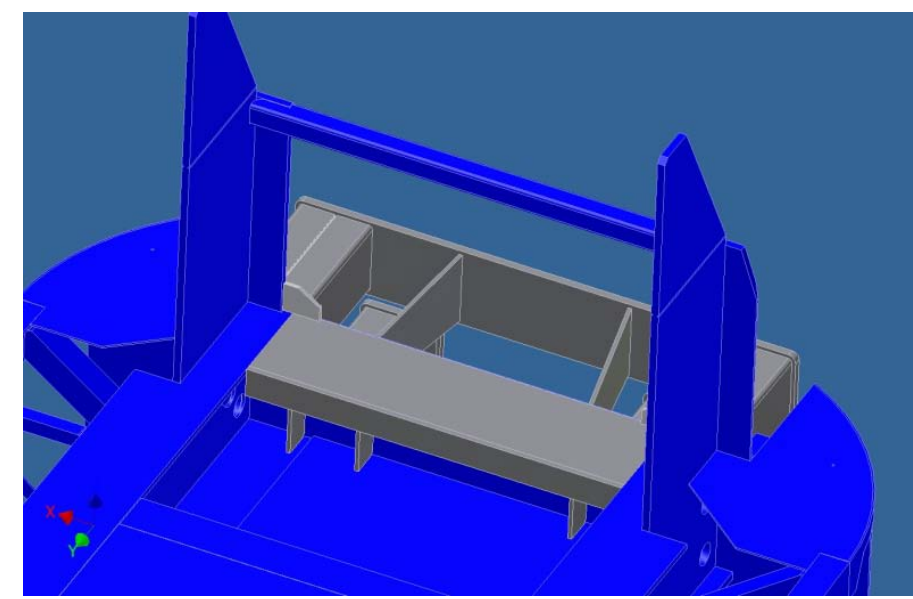

Figure 4. Deformable anti-climber (grey) and existing structure (blue).

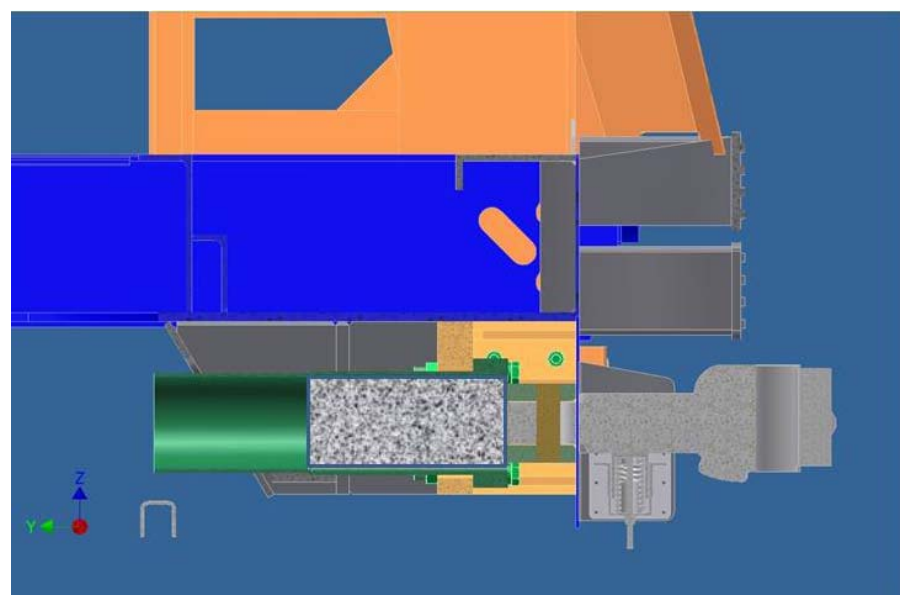

Figure 5. Side view of the deformable anti-climber/pushback coupler system retrofitted onto a MotivePower MP40.

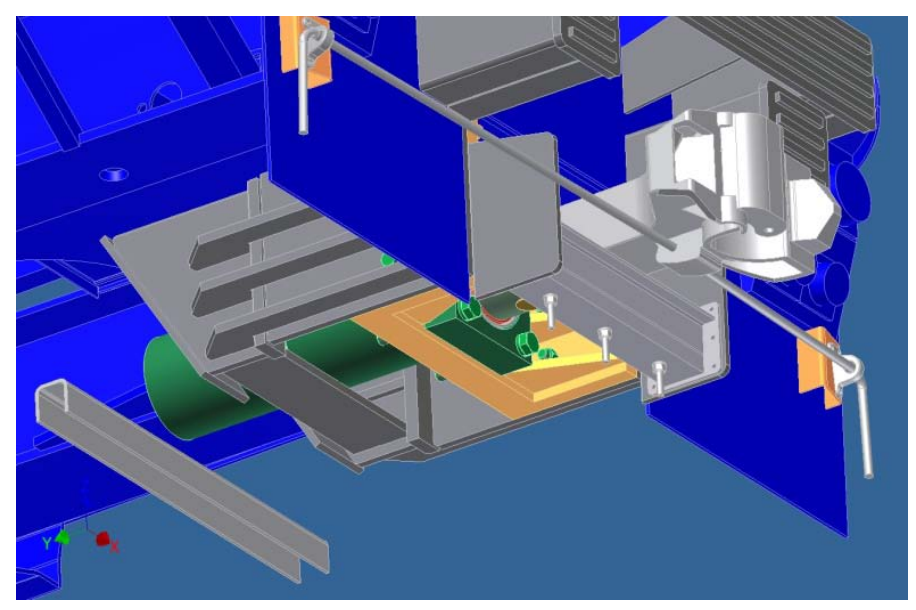

Figure 6. Bottom view of push-back coupler.

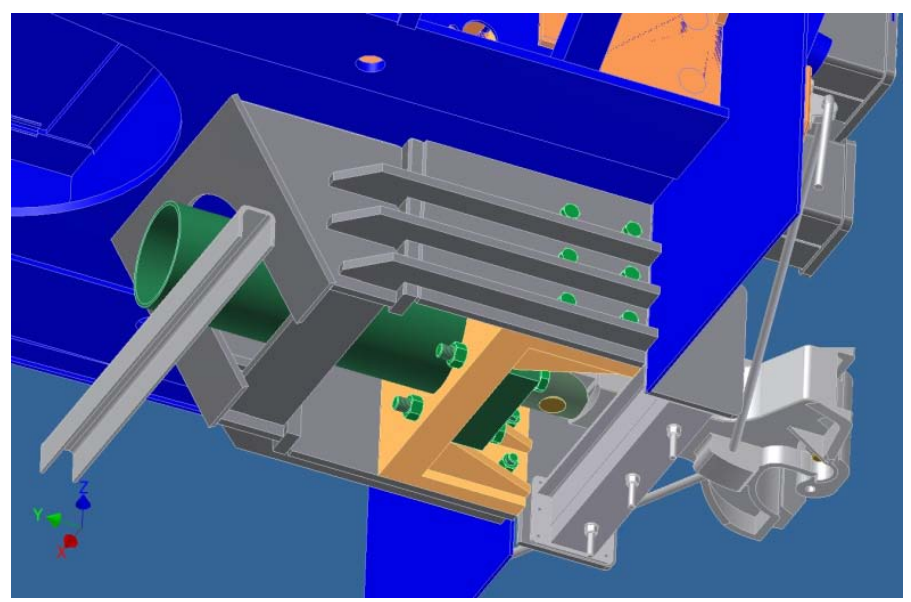

Figure 7. View of the shear bolts (green) that attach the push-back coupler to the sides of the draft gear pocket. 


\section{COLLISION SCENARIOS}

As stated in the design requirements, the consequences of three collision scenarios will be evaluated:

1. Modified locomotive to conventional locomotive

2. Modified locomotive to cab car

3. Modified locomotive to freight car

Each scenario will be evaluated for three conditions:

1. Vehicles perfectly aligned

2. Modified locomotive offset upward by 6.0 inches

3. Modified locomotive offset downward by 6.0 inches

The locations of initial contact between a modified locomotive and a conventional locomotive are illustrated in Figure 8. The nominal height contact is indicated in red and the +/-6-inch vertical offsets are indicated in orange. Note that the positioning of the upper progressive buckling tubes was motivated by the contact with the main beams of the underframe of the conventional locomotive. In this collision scenario, the lower progressive buckling tubes participate only in the -6-inch offset case, with very minor involvement. Figure 9 shows the interaction of the modified locomotive and the conventional locomotive after approximately 31 inches of relative displacement. In this preliminary diagram, the pushback coupler stroke has been exhausted after approximately 21 inches of deformation, and the deformable anti-climber has engaged with the underframe of the conventional locomotive with a predicted crush of approximately 11 inches.

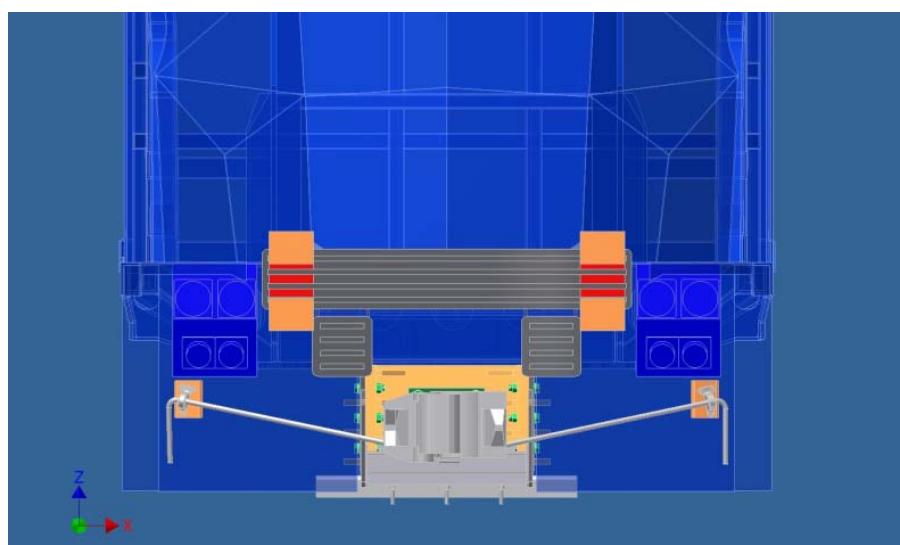

Figure 8. Modified locomotive initial contact with conventional locomotive $($ red $=$ nominal height, orange $=6$ inch offsets)

The locations of initial contact between a modified locomotive and a cab car are illustrated in Figure 10. The nominal height contact is shown in red and the +/-6-inch vertical offsets are shown in orange. Note that the positioning of the location of the lower progressive buckling tubes as well as the lateral connection between the upper progressive buckling tubes was motivated by the contact with the cab car end beam and collision posts. In this collision scenario, both the upper and lower progressive buckling tubes as well as the lateral connection are involved in all three cases (nominal and +/-6-inch offsets). Figure 11 shows the interaction of the modified locomotive and the cab car after approximately 31 inches of relative displacement. In this preliminary diagram, the push-back coupler stroke has been exhausted after approximately 21 inches, and the deformable anti-climber has engaged with the end beam and collision posts of the cab car, with a predicted crush of approximately 10 inches.

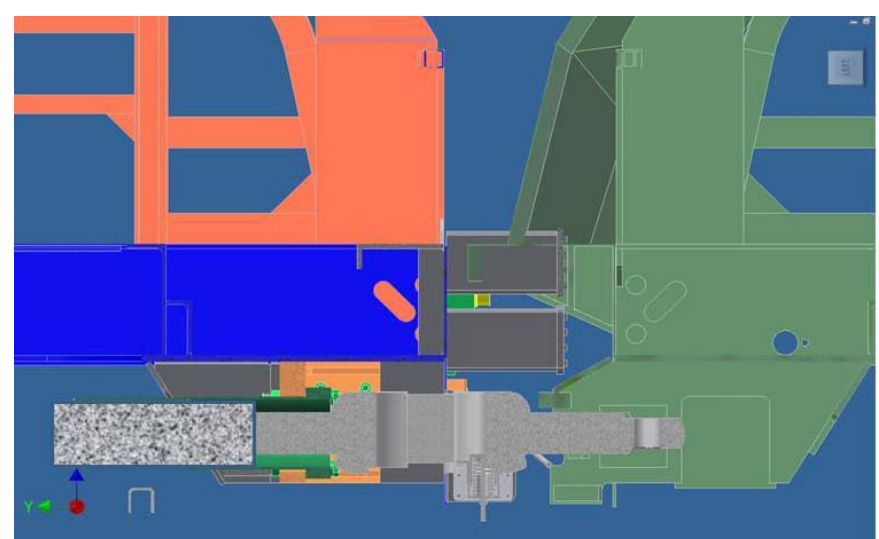

Figure 9. Interaction of modified locomotive (left) with conventional locomotive (right).

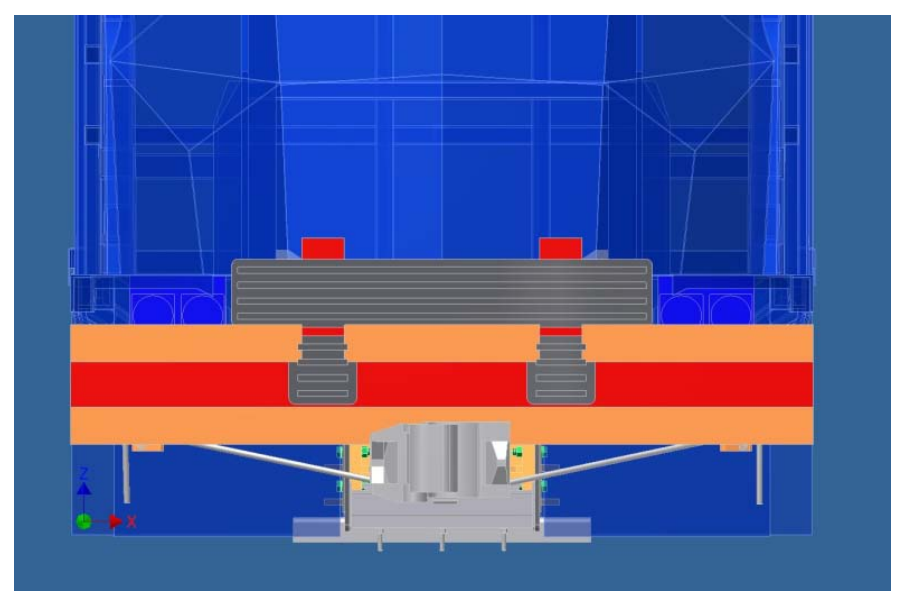

Figure 10. Modified locomotive initial contact with cab car (red $=$ nominal height, orange $=6$ inch offsets)

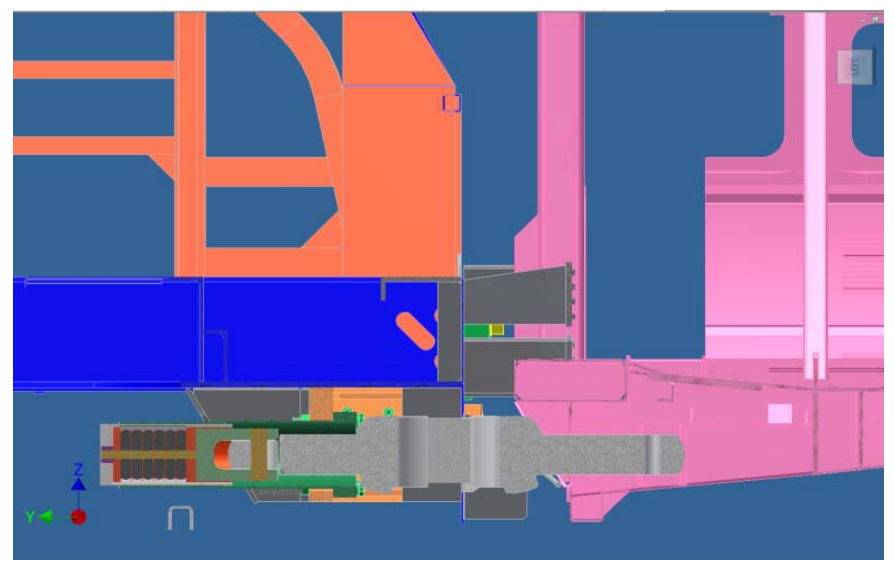

Figure 11. Interaction of modified locomotive (left) with cab car (right). 
Figure 12 shows the interaction of the modified locomotive and the freight car after approximately 31 inches of locomotive displacement. In this preliminary diagram, the push-back coupler has stroke has been exhausted after approximately 21 inches, but the deformable anti-climber has not engaged with any part of the freight car. Neither the upper nor the lower progressive buckling tubes are involved in the impact up to at least 31 inches of displacement. The freight car coupler extends so far forward of the front wall of the freight car that only the push-back coupler is involved in the collision at this level of relative vehicle displacement. In the evaluation of these collision scenarios, if it is deemed necessary to involve the deformable anti-climber/push-back coupler system in the collision, then the deformable anti-climber will be redesigned.

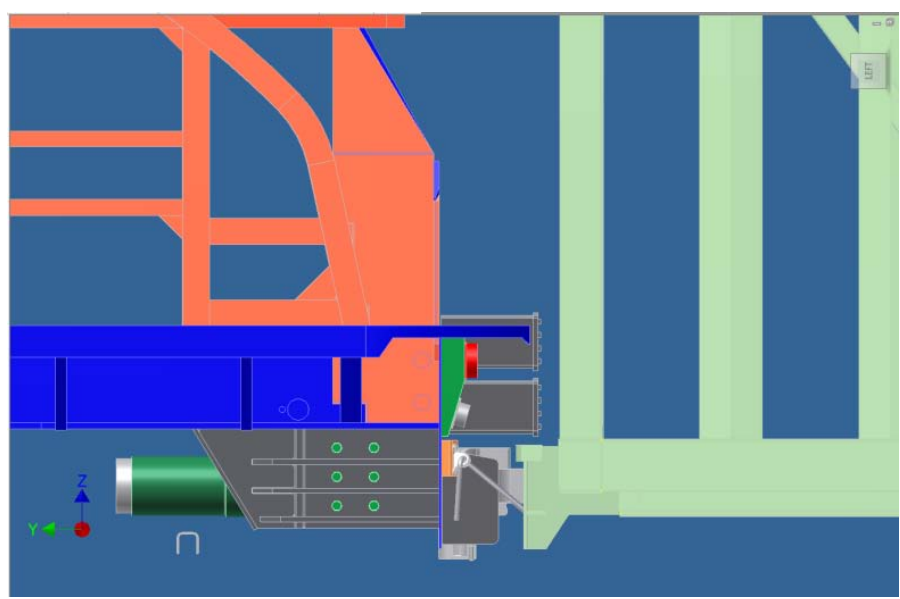

Figure 12. Interaction of modified locomotive (left) with freight car (right).

\section{PRELIMINARY FINITE ELEMENT MODELS}

At this point in the research program, finite element models have been generated for the conventional locomotive, the modified locomotive, the cab car, and the freight car. It is expected that the deformation will be concentrated at the impacting interface for all of the collision scenarios; therefore, detailed modeling is necessary only for the impacting vehicle ends. The remainder of each of the vehicles is modeled with progressively less mesh refinement and, in some cases, with simplified elements going backward into the vehicle. Only one side of all vehicles is modeled to take advantage of symmetry and to optimize computer run-time.

\section{Locomotive Models}

The finite element model of the conventional locomotive was developed based on a CAD model of an MP40 locomotive provided by MotivePower. The model was developed in ABAQUS/CAE and can be seen in Figure 13. Only one side was modeled to take advantage of symmetry and optimize computer run-time. As shown in Figure 2, much of the structure behind the hood of the locomotive and side wall is composed primarily of beams. These were modeled using beam elements in the finite element model, shown as red lines in Figure 13.
Figure 14 shows the finite element mesh of the front of the locomotive. The mesh is progressively refined toward the impacting end of this model in order to accurately predict the deformation of the structure in a collision, with a characteristic element length of 0.5 inches at the very front of the vehicle.

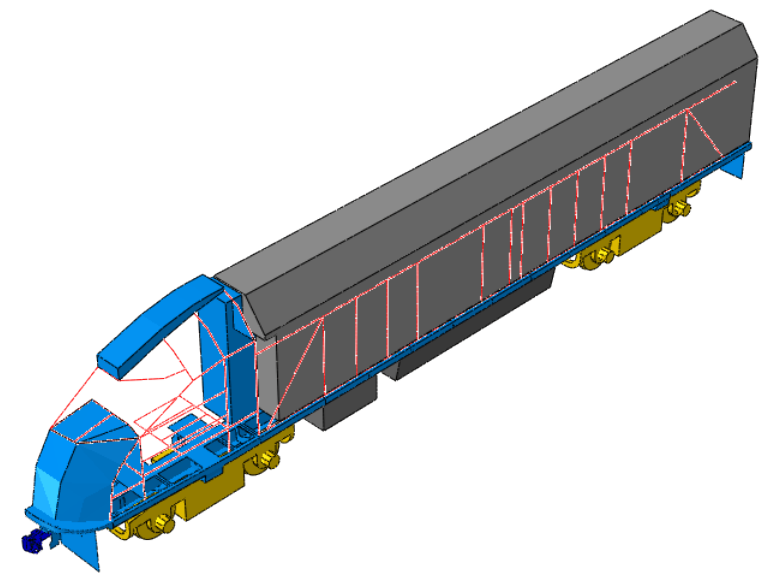

Figure 13. Finite element model of the conventional locomotive.

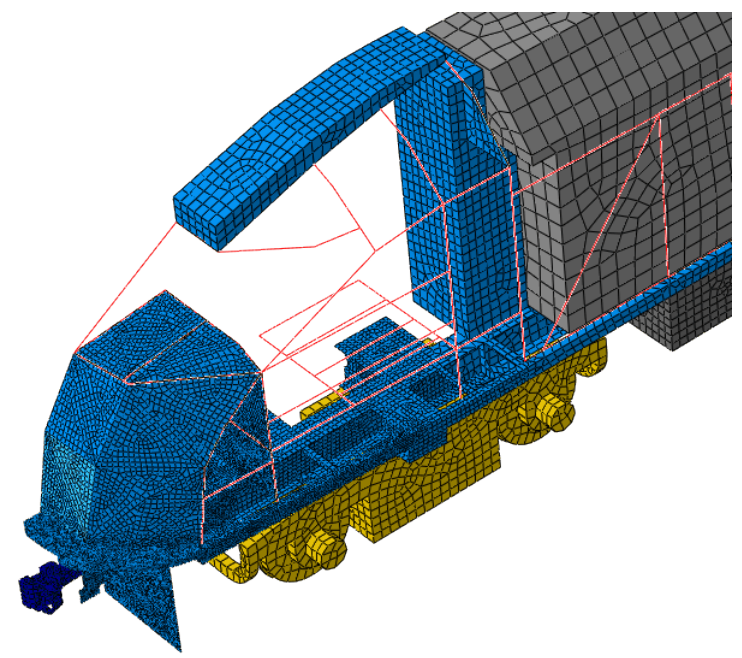

Figure 14. Front end of the finite element model of the conventional locomotive.

The finite element model of the modified locomotive was generated by starting with the conventional locomotive model and integrating the push-back coupler and deformable anticlimber into the front end. The front end of the finite element model can be seen in Figure 15. As in the conventional locomotive finite element model, the mesh is progressively refined toward the impacting end in order to accurately predict the deformation of the structure in a collision. The crush tubes have a characteristic element length of 0.25 inches.

Preliminary analyses have been conducted on the progressive buckling tubes that comprise the deformable anticlimber. These models were developed to evaluate their crush strength and vertical strength. Figure 16 shows the finite 
element model of a progressive buckling tube. The element size is approximately 0.25 inch in this model in order to accurately predict the deformation of the tube. Figure 17 shows a deformed progressive buckling tube.

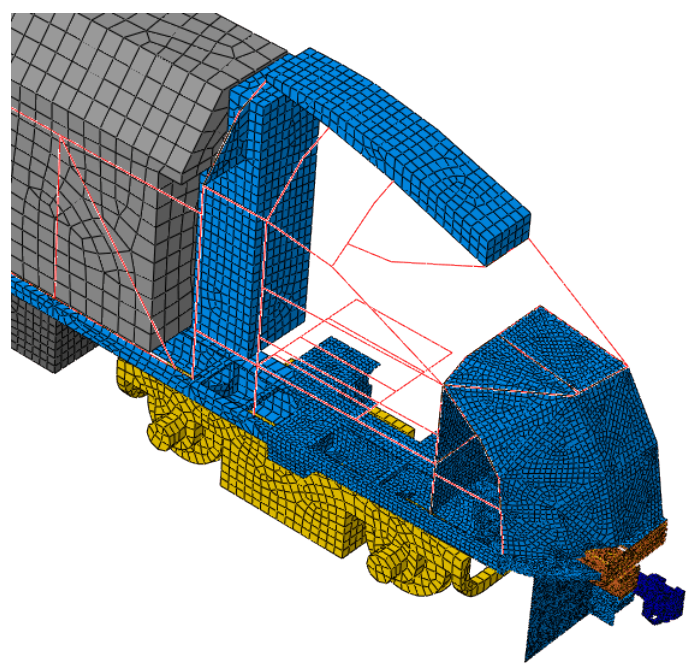

Figure 15. Finite element model of the modified locomotive.

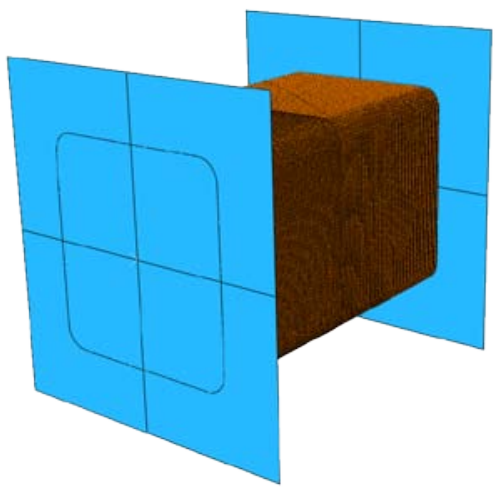

Figure 16. Finite element model of a progressive buckling tube.

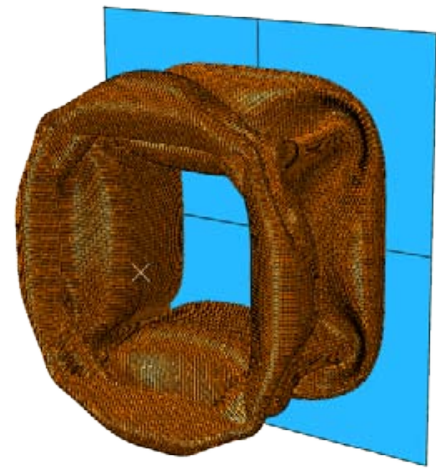

Figure 17. Deformed progressive buckling tube.

Preliminary dynamic analyses conducted at $15 \mathrm{mph}$ indicate that a stainless steel tube that is 10 inches $\mathrm{x} 10$ inches in crosssection, 17.25 inches long, and 0.3125 inches thick has an average crush strength of approximately 350,000 lbf. Additional analyses using this model indicate that the 100,000 lbf vertical load performance requirement can be easily supported by two undeformed tubes of these dimensions.

\section{Cab Car Model}

The finite element model of the cab car, shown in Figure 18, was developed by combining existing models of a complete Budd M1 cab car and a more detailed model of the end frame. Large deformation is expected in the area where the cab car first contacts the modified locomotive. The element mesh is very refined at this location, with an element size of approximately 0.25 inch, where the collision posts connect to the end beam as seen in Figure 19, in order to properly capture the deformation and failure expected. The element size increases to 1.0 inch for the remainder of the front end of the cab car and increases progressively towards the rear of the car.

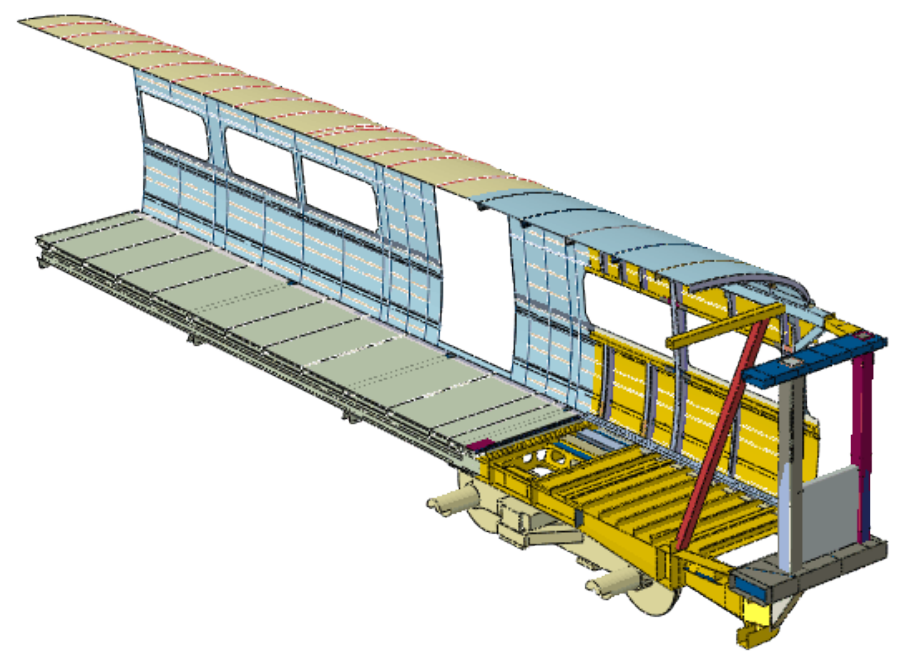

Figure 18. Cab car finite element model.

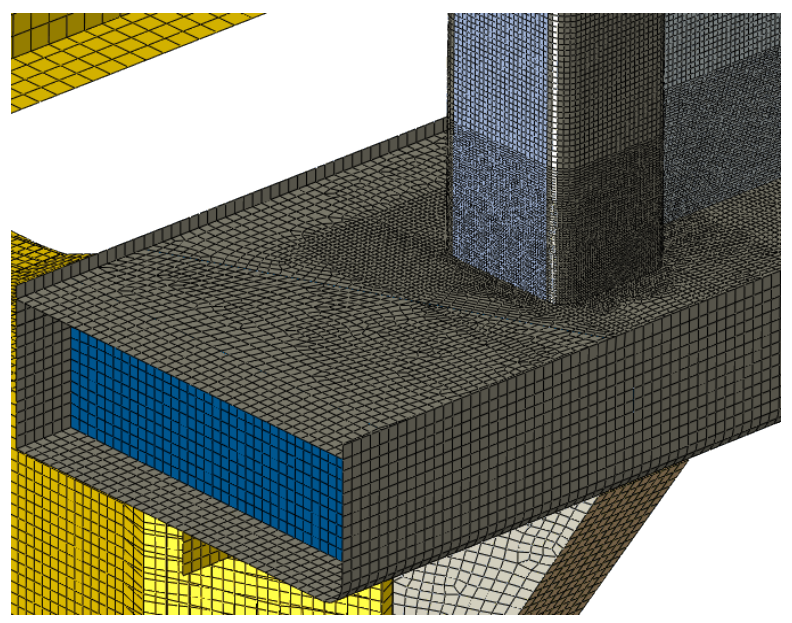

Figure 19. Mesh refinement at collision post connection to end beam. 
Preliminary analyses show that the cab car can support a load of approximately 1.0 million lbf prior to fracture when loaded about 8 inches above the end beam. Figure 20 shows the rigid form used to load the collision post in the analysis, and Figure 21 shows the resulting fracture at the base of the collision post. The rigid form has approximately the same height and width as the ribbed plate that connects the upper crush tubes of the deformable anti-climber. The resulting forcedisplacement curve of the analysis is shown in Figure 22. The peak load reaches 1.0 million lbf for the full-width car.

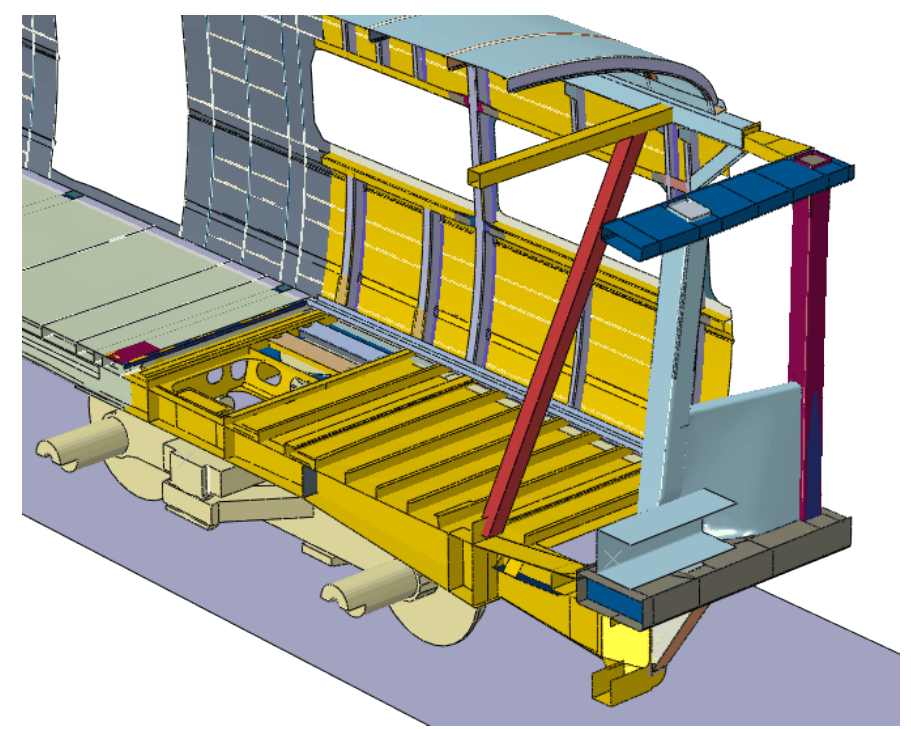

Figure 20. Collision post loaded $\sim 8$ inches above the end beam.

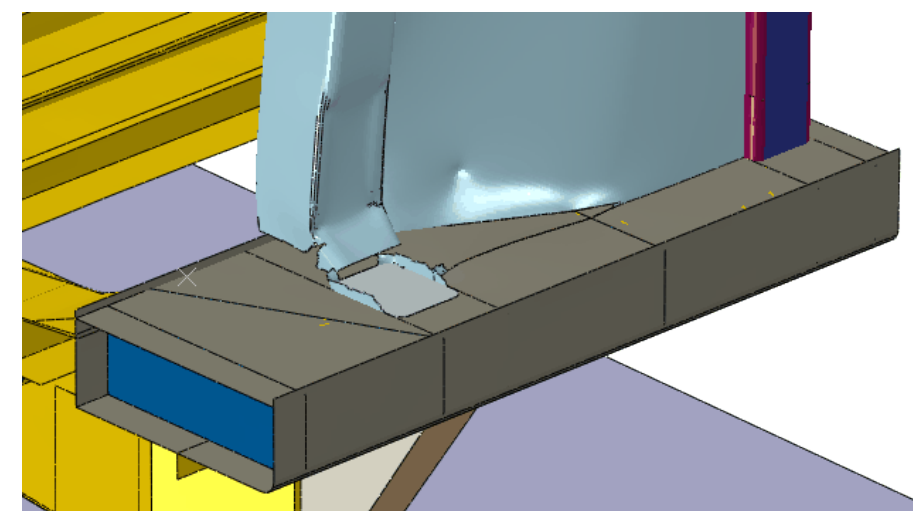

Figure 21. Fracture of collision post.

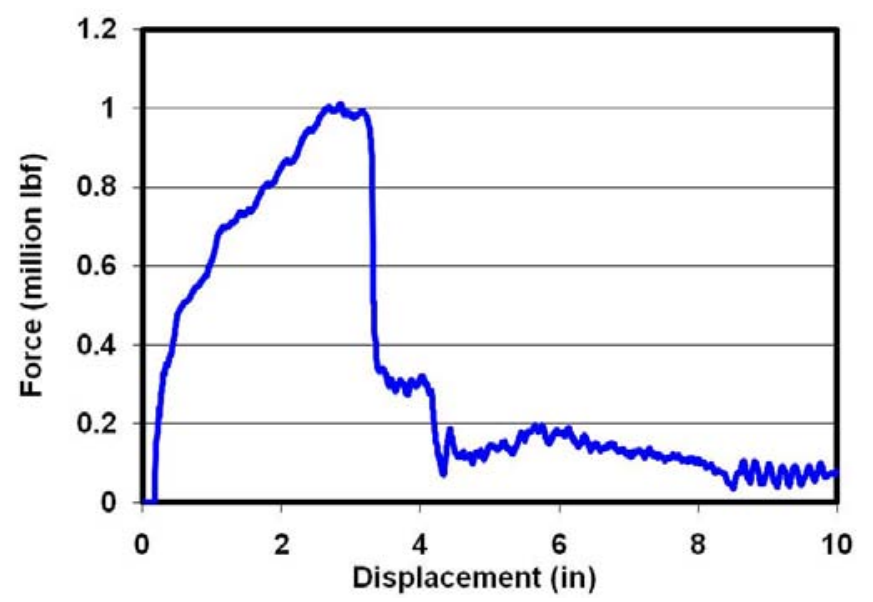

Figure 22. Force-displacement curve of cab car collision post deformation.

\section{Freight Car Model}

In light of the train collision in Canton, Massachusetts on March 25, 2008 between a locomotive-led passenger train and a freight train, a TrinityRail flat car was the freight car chosen for this project. A similar accident, with a collision between a locomotive and a flat car, occurred in Syracuse, New York on February 5, 2001. This type of freight car is composed of an underframe with two flat end walls connected by a spine running along the center-line of the car. The finite element model of the freight car, illustrated in Figure 23, was developed from drawings provided by TrinityRail. The global element size of the elements in this model is approximately 2 inches. The finite element mesh is shown in Figure 24. Preliminary analyses indicate that the freight car is very strong when loaded by a flat wall. The deformed freight car is shown in Figure 25. The flat wall has loaded the bellmouth of the draft gear and caused it to deform backwards. Figure 26 shows the forcedisplacement curve of the deformation and indicates a peak load of approximately 3.0 million lbf. A half-symmetric (one side) model of the freight car was used for the collision analyses to take advantage of symmetry and to optimize computer run-time.

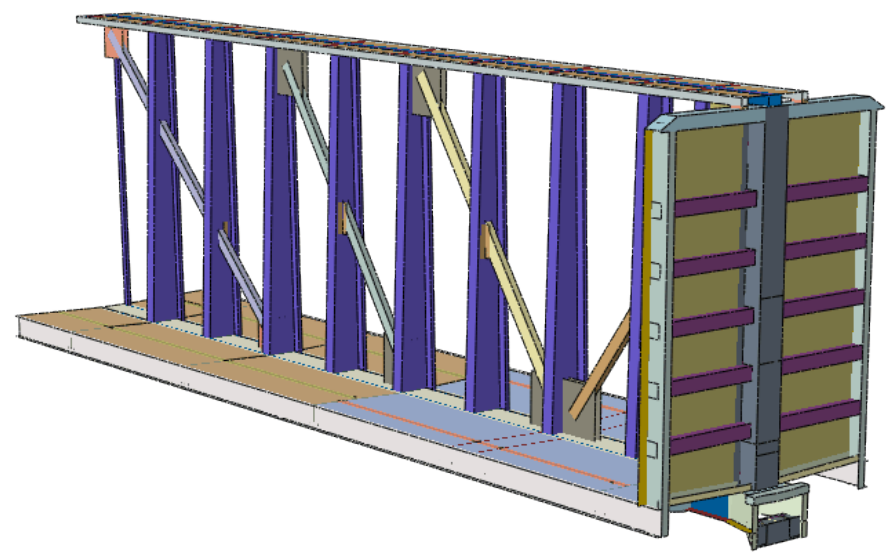

Figure 23. Freight car finite element model. 


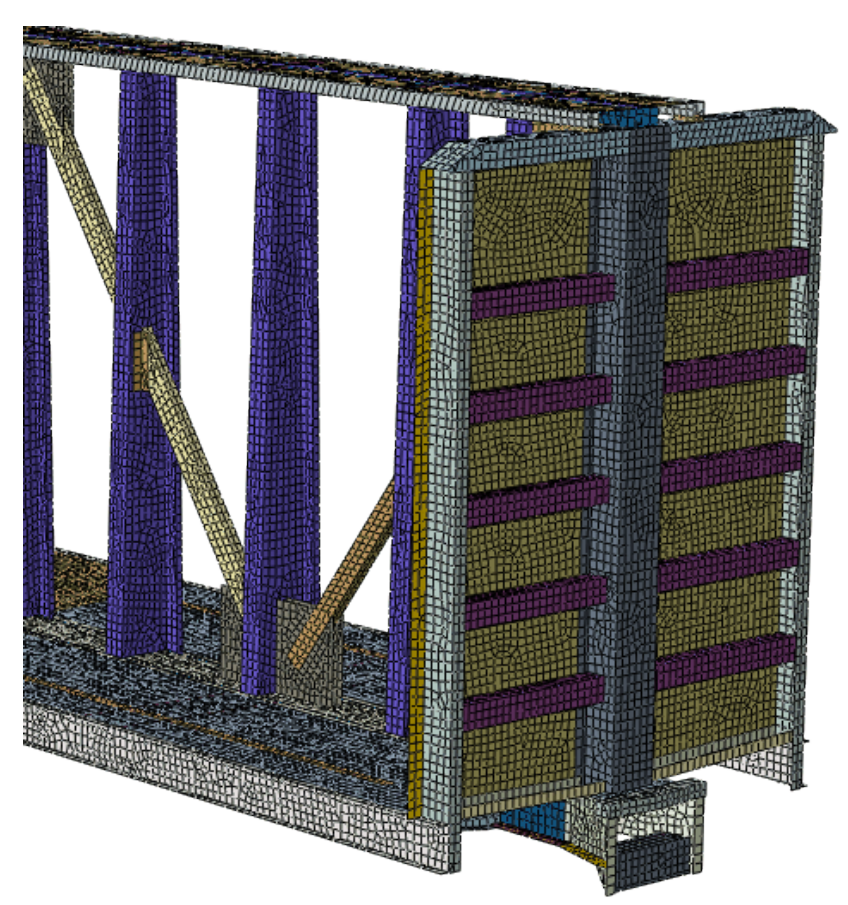

Figure 24. Finite element mesh of freight car.

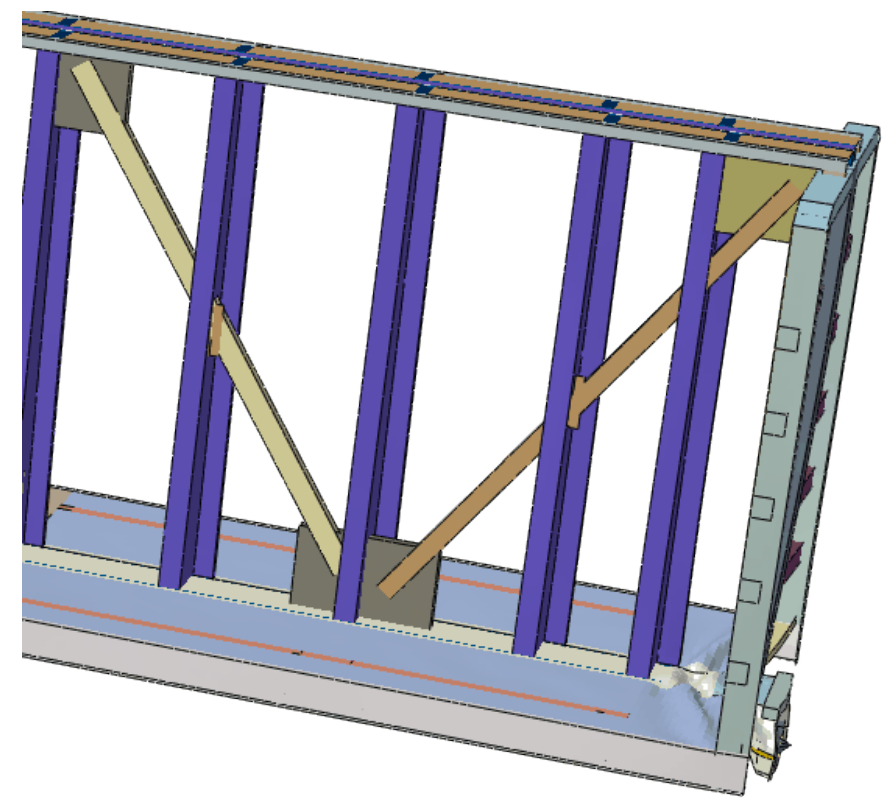

Figure 25. Deformed freight car model.

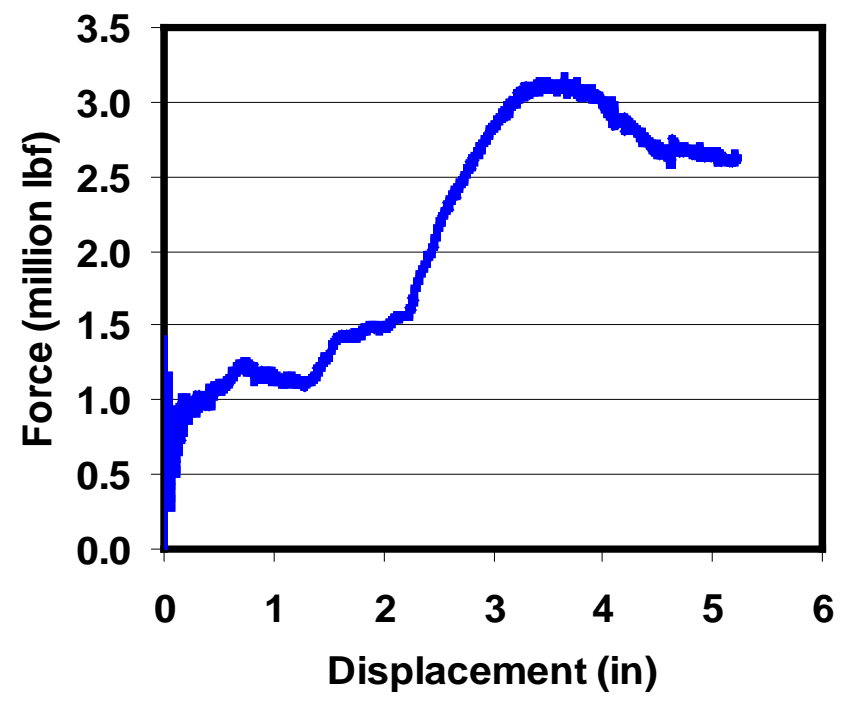

Figure 26. Force-displacement curve of freight car deformation.

\section{SUMMARY \& NEXT STEPS}

The Volpe Center is supporting the FRA in the development of a crash energy management (CEM) system for locomotives. In the event of a collision between two trains, one of the potential consequences is override of one of the vehicles onto the other. Research has shown that conventional locomotive anti-climbing structures can deform on impact and form a ramp, increasing the likelihood of override. The addition of a few structural features to the forward end of a locomotive, such as a push-back coupler and a deformable anti-climber, can greatly reduce the propensity for override.

Building on previous work, the objectives of the current research program are to develop detailed designs for a pushback coupler and a deformable anti-climber, develop test article designs for the components, construct the test articles, conduct the component tests, and refine the designs based on the results of the tests. The design requirements for a platform-style locomotive with increased crashworthiness due to the incorporation of a push-back coupler and a deformable anticlimber have been generated. These requirements govern the development of designs for push-back coupler and deformable anti-climber components, including the collision scenarios that will be used to evaluate their behavior in a collision with another vehicle. Preliminary designs and finite element models for the push-back coupler and deformable anti-climber have been completed. Preliminary finite element models of the conventional locomotive, the modified locomotive, the cab car, and the freight car have also been completed.

Any outstanding design issues will be resolved and the sizing and location of the progressive buckling tubes will be finalized. The trucks and truck connections will be included, as well as the coupler models for each vehicle. The vehicle models will be combined into one model for each of the three collision scenarios. A total of nine collision analyses will be conducted: nominal height plus the two vertical offset conditions for each 
of the three collision scenarios. Dynamic FEA will be performed using ABAQUS/Explicit to evaluate the performance of the draft designs against the design requirements. The dynamic force-crush characteristics and the modes of deformation of both vehicles will be calculated and compared to the design requirements. If the design requirements are not met, design revisions will be identified and the finite element models will be revised accordingly. The necessary dynamic analyses will be repeated and evaluated against the design requirements.

After conducting the FEA and determining that the design requirements have been met, test plans will be developed for testing the individual push-back coupler and deformable anticlimber components. This includes designing test article fixtures for both components. The push-back coupler and deformable anti-climber test articles will be sacrificial structures, designed to be dynamically tested, with each component built and tested separately. The test plan will include the approach for providing the required impact energy, the method of mounting the test articles, the key parameters to be measured and the instrumentation that will be used.

Finite element models for simulating the response of each of the component test article designs in the dynamic impact tests will be adapted from the finite element models of the draft designs. The test articles will be analyzed under the test conditions to generate pre-test predictions for the dynamic behavior of the components. These models will be used to determine the input energy required to deform the test articles to their final configuration. The force/deformation characteristics and mode shapes for the test article designs will be compared to the force/deformation characteristics and mode shapes for the draft designs. Revisions will be made to the test article designs as necessary. Once the test article designs are finalized, part and assembly drawings and construction sequences for the two component test articles and fixtures will be completed.

Based on the fidelity of the test article designs to the draft designs, the test articles and test fixtures will be fabricated and assembled using typical railroad industry practice. Quality control reviews will be conducted to assure that the test articles and test fixtures are fully compliant with the part drawings, specified materials and rail industry standard construction methods. Particular attention will be paid to the quality of the welds and to the location and installation of any elements that are seen as critical to the performance of the design, such as the shear bolt holes and shear bolts.

A test implementation plan (TIP) will be developed for each component test article. The test articles and test fixtures, all instrumentation, and the data acquisition system will be installed. The component tests will be conducted according to the TIP and data will be collected before, during, and after the tests. A thorough review and analysis of the test data will be conducted. All test data will be filtered and processed to extract the force-deformation and strain-deformation characteristic for each test. High-speed video images will be captured at various intervals to correspond to the crush values for which FEA results are available.

Selected test measurements will be compared with the pretest predictions, particularly the force-time and deformationtime histories, as well as the force/deformation characteristic, for each test article. Comparisons between the pre-test predictions and the test measurements will also be made for other selected measurements. The level of performance measured during the test will be compared with the required performance of the components. If there is a large variation in the maximum deformation between the component tests and the predictions, recommendations on design modifications will be provided.

\section{ACKNOWLEDGEMENTS}

This work was performed under contract to the Volpe Center as part of the Equipment Safety Research Program sponsored by the Office of Research and Development of the Federal Railroad Administration. The authors appreciate the support and guidance offered by Kevin Kesler, Chief of the Equipment and Operating Practices Division, and David Tyrell, the Crashworthiness Team Leader at the Volpe Center. The authors would like to thank Gabriel Amar of Taylor Raynauld Amar \& Associates for his contribution to the contract effort. A CAD model of an MP40 locomotive was provided by MotivePower. Drawings of the freight car were provided by TrinityRail.

\section{REFERENCES}

[1] Tyrell, D., Severson, K., Marquis, B., Martinez, E., Mayville, R., Rancatore, R., Stringfellow, R., Hammond, R., Perlman, A.B., "Locomotive Crashworthiness Design Modifications Study," Proceedings of the 1999 IEEE/ASME Joint Railroad Conference, Institute of Electrical and Electronics Engineers, Catalog Number 99CH36340, 1999.

[2] Mayville, R., Stringfellow, R., Johnson, K., Landrum, S., "Crashworthiness Design Modifications for Locomotive and Cab Car Anticlimbing Systems," US Department of Transportation, DOT/FRA/ORD-03/05, February 2003.

[3] The American Public Transportation Association, APTA SS-C\&S-034-99, Rev 2, Standard for the Design and Construction of Passenger Railroad Rolling Stock”, 2006.

[4] Association of American Railroads, AAR S-580 Standard, "Locomotive Crashworthiness Requirements," adopted December 2004, revised 2008.

[5] Code of Federal Regulations, Title 49, Part 229, "Railroad Locomotive Safety Standards”.

[6] The American Public Transportation Association, APTA RP-C\&S-XXX, Recommended Practice for Push-back Couplers in Passenger Rail Equipment, draft as of 7/1/08. 